\title{
TEMPO E CONCEITO: ARENDT, LEITORA DE HEGEL ${ }^{1}$
}

\author{
Nuno Pereira Castanheira ${ }^{2}$ \\ José Pinheiro Pertille ${ }^{3}$
}

\section{Resumo:}

A obra de Hannah Arendt tem uma forte presença hegeliana, seja em virtude de convergências temáticas, seja em virtude de divergências fundamentais do ponto de vista metodológico, ontológico e político. Salvaguardadas as diferenças de detalhe no tratamento dessas questões, as convergências temáticas fazem-se notar na distinção entre social e político e no lugar que a singularidade ocupa nas suas teorias políticas. A sua divergência fundamental diz respeito à filosofia da história, à noção de temporalidade que lhe está associada e às suas consequências para a relação entre necessidade, contingência e liberdade, bem como à noção de Progresso. O texto que aqui se apresenta procura contribuir para a clarificação desta divergência, argumentando que nela se constitui o eixo sobre o qual se articula a cisão entre os dois pensamentos.

Palavras-Chave: Arendt. Hegel. Tempo. Conceito. Hegelianismo Metafísico.

\section{TIME AND CONCEPT: ARENDT, READER OF HEGEL}

\begin{abstract}
:
Hannah Arendt's work contains a strong Hegelian presence both in virtue of their thematic convergence and their basic divergences from a methodological, ontological and political viewpoint. Differences regarding the detailed treatment of those issues notwithstanding, the thematic convergences are particularly evident vis-à-vis the distinction between the social and the political, as well as the place attributed to singularity in their political theories. Their basic divergence regards the philosophy of history, the notion of time related to it and its consequences for the relation between necessity, contingency and freedom, as well as the notion of Progress. This paper intends to contribute to the clarification of this divergence, arguing that it constitutes the point of articulation of the schism between both thoughts.
\end{abstract}

Keywords: Arendt. Hegel. Time. Concept. Metaphysical Hegelianism.

\section{NOTA INTRODUTÓRIA}

O pensamento de Arendt não se inscreve e não poderia inscrever-se, em virtude da atitude fundamentalmente anti-académica e avessa ao pensamento de escola

1 O presente texto foi desenvolvido no âmbito do projecto "A filosofia politica de Hannah Arendt à luz da filosofia especulativa de Hegel", coordenado pelo Professor Doutor José Pinheiro Pertille, no âmbito das actividades de pesquisa do Programa de Pós-Graduação em Filosofia da Universidade Federal do Rio Grande do Sul.

2 Doutor em Filosofia, pós-doutor da Universidade Federal do Rio Grande do Sul/Universidade de Lisboa: nuno.castanheira@ufrgs.br / CV Lattes: http://lattes.cnpq.br/2074282295154166.

3 Doutor em Filosofia, Professor da Universidade Federal do Rio Grande do Sul: jper@ufrgs.br / CV Lattes: http://lattes.cnpq.br/3464974998232888. 
que governa a sua obra, em qualquer "ismo". A experiência de Arendt enquanto estudante de filosofia na universidade alemã da década de 1920 colocou-a em contacto com um conjunto de "ismos" - vários tipos de cientificismos e de formalismos - entre os quais se interpunha uma nuvem nostálgica em torno de Hegel e de um retorno à metafísica e aos seus absolutos na qual a pensadora nunca se viu reflectida. Arendt nunca teve grande estima pelas sínteses totalizadoras sistemáticas que procuravam emular Hegel na universidade dos seus tempos de estudante, considerando que eram meros sucedâneos metafísicos, pretensiosos e limitadores ${ }^{5}$.

Hannah Arendt não pode, por isso, ser classificada como neohegeliana.

Todavia, isso não significa que Hegel ele mesmo, e não apenas os seus contemporâneos hegelianos, fosse um desconhecido para Arendt ou que não tenha um lugar relevante no desenvolvimento do seu pensamento. De facto, Arendt foi uma leitora atenta de Hegel, com cuja obra manteve um interessante diálogo cujos contornos são ainda hoje significativos.

Durante o período que passou em França tentando escapar ao regime nazista, Arendt frequentou os seminários de Alexandre Kojève sobre Hegel realizados na École des Hautes Études, considerando que a sua Introduction à la lecture de Hegel ${ }^{6}$ era crucial para todos aqueles que estivessem interessados em compreender o filósofo alemão $^{7}$ e, por extensão, o movimento fundamental de toda a filosofia moderna. Na sua biografia de Arendt, Laure Adler relata o seguinte:

Hannah revê Raymond Aron, assiste aos seminários de Alexandre Kojève sobre Hegel, onde se cruza com Sartre, tem longas conversas com Jean Wahl, que introduziu o pensamento de Karl Jaspers na França, e com Alexandre Koyré, que colabora para a revista Recherches Philosophiques. ${ }^{8}$

4 Traços dessa atitude estão dispersos por toda a obra de Arendt, desde entrevistas que se apoiam em experiências pessoais até às críticas mais profundas e teoricamente fundamentadas à atitude filosófica tradicional para com a política. Vejam-se, por exemplo, Hannah Arendt, Essays in Understanding: 1930-1954 Formation, Exile, and Totalitarianism, ed. Jerome Kohn (New York: Schocken Books, 1994) e Hannah Arendt, The Human Condition (Chicago: University of Chicago Press, 1959).

5 Elisabeth Young-Bruehl, Hannah Arendt: For Love of the World (New Haven: Yale University Press, 1982), 45.

${ }^{6}$ Alexandre Kojève et Raymond Queneau, Introduction à la lecture de Hegel: leçons sur la "Phénoménologie de l'esprit" professées de 1933 à 1939 à l'École des Hautes Études (Paris: Gallimard, 1979).

7 Young-Bruehl, Hannah Arendt: For Love of the World, 116-17.

8 Laure Adler, Nos Passos de Hannah, traduzido por Tatiana Salem Levy e Marcelo Jacques (Rio de Janeiro; São Paulo: Editora Record, 2007), 140.

\begin{tabular}{|l|l|l|l|l|}
\hline Qevista Dialectus & Ano 5 & n. 12 & Janeiro - Julho 2018 & p. 374-399 \\
\hline
\end{tabular}


Desses encontros resultou uma amizade com Alexandre Koyré, cuja interpretação da obra hegeliana serviu de base às suas discussões em torno da vontade sempre que estas envolviam elementos hegelianos ${ }^{9}$.

Ademais, o facto de Arendt não ser uma neohegeliana significa ainda menos que a presença de Hegel na sua obra - implícita ou explicitamente - seja negligenciável ou que este não constitua um diálogo a respeito de uma situação que é ainda e também a nossa, por razões que procuraremos tornar claras ao longo deste texto.

Podemos efectivamente encontrar em Arendt uma análise do domínio social e a sua distinção do domínio do político que encontra precedente, ainda que com diferenças assinaláveis, na Filosofia do Direito $^{10}$ de Hegel, nomeadamente na sua distinção conceitual entre Estado (Staat) e Sociedade Civil Burguesa (bürgerliche Gesellschaft).

Em termos de história da filosofia, isso substitui o modelo jusnaturalista de pensar a sociedade política mediante um contrato que marca o fim do estado de natureza, e completa o movimento de reacção a essa perspectiva iniciado por Adam Ferguson em seu Ensaio sobre a história da sociedade civil ${ }^{11}$ (1767).

Segundo Hegel, o Estado não deve ser confundido com a sociedade, como se ele tratasse fundamentalmente de assegurar e proteger a propriedade e a liberdade pessoal. Ao contrário, o Estado é a racionalidade concreta na medida em que se compenetram a vontade substancial universal e a liberdade subjectiva que tem aqui o seu saber individual e busca os seus fins particulares; essa é a unidade da liberdade objectiva $^{12}$. Compreendendo o que Hegel chama de Estado como uma esfera pública distinta dos interesses privados da sociedade civil, essa não deixaria de ser uma equação similar à buscada pelo raciocínio de Arendt.

Um outro aspecto partilhado por Arendt e Hegel é o lugar central que atribuem à questão da singularidade, a qual tem um papel central no terreno da acção e da política. Como ser um indivíduo sem ser individualista? Ou, como contornar a

9 Hannah Arendt, «Willing» in The Life of the Mind, ed. Mary MacCarthy, One Volume (New York: Harcourt, Inc., 1978), p. 40.

${ }^{10}$ G.W.F. Hegel, Grundlinien der Philosophie des Rechts, Naturrecht und Staatswissenschaft im Grundrisse - Grundlinien der Philosophie des Rechts. Gesammelte Werke 14, herausgegeben von Klaus Grotsch und Elisabeth Weisser-Lohmann (Frankfurt am Main: Meiner Verlag, 2009).

11 Adam Ferguson and Fania Oz-Salzberger, An Essay on the History of Civil Society (Cambridge: Cambridge University Press, 1995).

12 Hegel, Grundlinien der Philosophie des Rechts, Naturrecht und Staatswissenschaft im Grundrisse Grundlinien der Philosophie des Rechts. Gesammelte Werke 14, § 258 Observação.

\begin{tabular}{|l|l|l|l|l|}
\hline Qovista Q Dialectus & Ano 5 & n. 12 & Janeiro - Julho 2018 & p. 374-399 \\
\hline
\end{tabular}


metafísica da subjectividade, de modo a possibilitar o engendramento da esfera pública, levando em conta o desaparecimento do modelo dos antigos e o estabelecimento da subjectividade moderna? Cada um a seu modo próprio, tanto Hegel quanto Arendt responderiam: fazendo-se singular.

O conceito de singularidade é um conceito técnico em ambos. Para Arendt, o que vai possibilitar uma diferenciação entre as esferas privada e pública, sem recorrer às antigas instituições da família e do Estado, é um tipo de actividade específico, diferente das restantes actividades, o trabalho e a obra ${ }^{13}$. É a acção que institui os corpos políticos e que revela o que de mais específico tem o ser humano: ser um singular numa pluralidade, constituída com as suas palavras e feitos:

\begin{abstract}
O facto de que o homem é capaz de agir significa que se pode esperar dele o inesperado, que ele é capaz de realizar o infinitamente improvável. E isto, por sua vez, só é possível porque cada homem é singular, de sorte que, a cada nascimento, vem ao mundo algo singularmente novo. Desse alguém que é singular pode-se verdadeiramente dizer que antes dele não havia ninguém. Se a acção, como começo, corresponde ao facto do nascimento, se é a efectivação da condição humana da natalidade, o discurso corresponde ao facto da distinção e é a efectivação da condição humana da pluralidade, isto é, do viver como ser distinto e singular entre iguais ${ }^{14}$
\end{abstract}

Para Hegel, a consciência de si singular alça o indivíduo como centro de gravidade da teoria do espírito objectivo. Isso pode ser visto de maneira significativa no acréscimo que Hegel faz, na $3^{\mathrm{a}}$ edição da Enciclopédia das Ciências Filosóficas ${ }^{15}$, da rubrica do "espírito livre" como a passagem do espírito subjectivo em direcção ao espírito objectivo. A passagem faz-se quando a vontade consegue suprassumir os extremos da repetição dos conteúdos dados, práticos, rotineiros e finitos, e da determinação infinita da vontade que se quer e se pensa livre; a vontade livre assim se faz «singularidade imediata, posta por si, mas depurada na determinação universal da liberdade mesma» ${ }^{16}$. A mediação mais elevada do espírito subjectivo é ultrapassar as oposições entre pensamento e vontade, contemplação e acção, teoria e prática. Para isso,

13 Usamos aqui a opção de tradução de Labor/Trabalho, Work/Obra, Action/Acção sugerida por Adriano Correia na sua revisão técnica à tradução de Roberto Raposo da obra arendtiana $A$ Condição Humana. Veja-se Hannah Arendt, A Condição Humana, tradução de Roberto Raposo com revisão técnica de Adriano Correia, $12^{\mathrm{a}}$ (Rio de Janeiro: Forense Universitária, 2014).

14 Hannah Arendt, The Human Condition, 1959, 178.

15 G.W.F. Hegel, Enzyklopädie der philosophischen Wissenschaften im Grundrisse (1830) Gesammelte Werke 20, herausgegeben von Wolfgang Bonsiepen und Hans Christian Lucas (Frankfurt am Main: Meiner Verlag, 1992).

16 Ibid., § 481 .

\begin{tabular}{|c|c|c|c|c|}
\hline Q Rovita Dialactus & Ano 5 & n. 12 & Janeiro - Julho 2018 & p. $374-399$ \\
\hline
\end{tabular}


é preciso que cada "singularidade" receba seus conteúdos particulares e coloque em acção suas determinações particulares e universais para «receber um mundo e fazê-lo seu» ${ }^{17}$. Em termos mais hegelianos, a ideia aparece na vontade finita que é a actividade de desenvolvê-la, de pôr seu conteúdo desdobrando-se como ser-aí, que como ser-aí da ideia é efectividade. Este é o espírito objectivo, o qual jamais perde de vista o indivíduo singular.

Como parte das notas características da acção do indivíduo singular também está presente para Hegel e Arendt o carácter da imprevisibilidade da acção. Este é um ponto correctamente ressaltado por Allen Speight em seu artigo Arendt and Hegel on the tragic nature of action ${ }^{18}$, representativo de uma leitura ainda incipiente, mas que busca uma compreensão mais qualificada das influências de Hegel sobre Arendt. Segundo Speight, a tematização hegeliana da imprevisibilidade da aç̧ão pode ser encontrada na noção de acção ética ${ }^{19}$ e suas inesperadas consequências trágicas, tal como isso aparece nas acções de Antígona e de Creonte que levam ao colapso da pacífica organização e movimento do mundo ético grego antigo, e que conduzem à questão do que pode ser esquecido ou reconciliado na acção. A acção é sempre uma acção em aberto para um variegado de possibilidades.

No entanto, como ideia para um debate, também poderíamos retomar esse mesmo ponto partindo da distinção hegeliana entre ato e acção, Tat e Handlung ${ }^{20}$ : a expressão exterior da vontade enquanto subjectiva ou moral é a acção, Handlung, diferentemente do fazer ou do operar em geral, Tun, e da actividade voltada para a objectividade, Tätigkeit. O agir, Handeln, é determinado a partir da subjectividade, ou daquilo que ela se propõe, do que ela intenciona. Na "acção moral" trata-se, sobretudo, da relação do sujeito às normas segundo as quais ele age, e não de suas performances efectivas, o que abre caminho para um aspecto que se poderia chamar de "acção ética", na medida em que a intencionalidade está aberta para o terreno da contingência.

Estes são exemplos de pontos de cruzamento dos pensamentos de Arendt e de Hegel cuja exploração pode revelar-se proveitosa, mas não serão o foco deste artigo.

17 Ibid., $\$ 482$.

18 A. Speight, "Arendt and Hegel on the Tragic Nature of Action," Philosophy \& Social Criticism 28, no. 5 (2002): 523-36.

19 G.W.F. Hegel, Phänomenologie des Geistes. Gesammelte Werke 09, herausgegeben von Wolfgang Bonsiepen und Reinhard Heede (Frankfurt am Main: Meiner Verlag, 1980), capítulo VI.

20 Hegel, Grundlinien der Philosophie des Rechts, Naturrecht und Staatswissenschaft im Grundrisse Grundlinien der Philosophie des Rechts. Gesammelte Werke 14, §113 da secção Moralidade.

\begin{tabular}{|l|l|l|l|l|}
\hline Q Rovista Dialectus & Ano 5 & n. 12 & Janeiro - Julho 2018 & p. 374-399 \\
\hline
\end{tabular}


Partindo da premissa de que este é um diálogo frutuoso cujos contornos ainda pertencem essencialmente à nossa situação, é nossa intenção, neste texto, traçar um dos horizontes mais recursivos e polémicos desse encontro entre Arendt e Hegel, aquele que vincula a relação estabelecida pela filosofia hegeliana entre o conceito e o tempo no quadro de uma filosofia da história.

\section{A RELAÇÃo COM A CONTINGÊNCIA COMO HORIZONTE}

Num conjunto de notas datadas de $1952^{21}$, Arendt parece indicar que a tarefa do filósofo, nos nossos dias, consiste em dar conta da ruptura entre o Ser ou o Mundo e o Pensar ou a Ideia. Para Arendt, foi Kant quem estilhaçou esta unidade entre Pensar e Ser, «[roubando] ao homem a sua antiga segurança no Ser $[\ldots] »$ ao provar que «[...] numa proposição que faça uma afirmação acerca da realidade, alcançamos para lá do conceito (essentia) de qualquer coisa dada $»^{22}$.

Segundo Kant, a existência não é um predicado das coisas, isto é, a existência não é uma propriedade que possa derivar-se necessária e universalmente por via da mera análise do conceito de uma coisa. Em termos kantianos, a verdade ou validade objectiva de qualquer juízo de conhecimento - cujos critérios são a necessidade e a universalidade - refere-se apenas à adequação entre a forma do juízo e o conceito ou síntese de representações que constitui o objecto dado na experiência; essa validade objectiva nada nos diz a respeito da sua existência como coisa.

No entanto, Kant afirma também que «[...] as condições de possibilidade da experiência em geral são, ao mesmo tempo, condições de possibilidade dos objectos da experiência e têm, por isso, validade objectiva num juízo sintético a priori» ${ }^{23}$. Isto significa que não seria possível representar qualquer objecto por intermédio dos conceitos puros do entendimento numa estrita independência com respeito às condições espácio-temporais da sensibilidade, pois tal implicaria uma ausência das condições da sua realidade objectiva. E é justamente a realidade do objecto que assenta na sua existência possível em estrita independência da mente, isto é, na sua existência como coisa. Em suma, a existência tem de estar sempre já dada enquanto possibilidade e isso

21 Hannah Arendt, "The Spiritual Quest of Modern Man_The Answer of the Existentialists," Hannah Arendt Papers at the Library of Congress, 1952, http://memory.loc.gov/cgibin/ampage collId $=$ mharendt $\&$ fileName $=05 / 052280 / 052280$ page. db\&recNum $=0$.

22 Arendt, Essays in Understanding: 1930-1954 Formation, Exile, and Totalitarianism, 168.

23 Immanuel Kant, Bd 3 (I/3) Kritik der reinen Vernunft, (2. Aufl. 1787), (Berlin; Boston: De Gruyter, 1962), B197.

\begin{tabular}{|c|c|c|c|c|}
\hline Rovista Dialectus & Ano 5 & n. 12 & Janeiro - Julho 2018 & p. 374-399 \\
\hline
\end{tabular}


implica que a realidade está sempre dependente de algo que pode ou não ser o caso: a realidade é fundamentalmente contingente. Nas palavras de Arendt, «a ciência [...] já não entrega qualquer [...] verdade de interesse para o homem $»^{24}$, dado que parece ser incapaz de dar conta do simples facto de existirmos sem razão.

O resultado desta perspectiva é que a filosofia não trata mais das essências das coisas, «[...] deixando isso às ciências, mas do Isto da sua existência» ${ }^{25}$. Ou seja, podemos pensar o que quisermos acerca da realidade, mas esta estará sempre condicionada pelo facto de o nosso acesso a ela ser constitutivamente contingente, isto é, infundado ou sem razão, constituindo-se assim o horizonte de possibilidade da autodeterminação do humano. Ao afirmar que o ser humano pode aceder a uma dimensão de realidade à qual não se chega por intermédio do mero conhecimento, Kant abre espaço para a autonomia do humano, a sua capacidade de se arrancar à causalidade natural e de se compreender no contexto de leis dadas por si a si mesmo, isto é, no contexto da política e da liberdade.

O ser humano parece, assim, poder desfrutar de uma liberdade desprovida de quaisquer limitações provenientes de uma necessidade de origem natural ou religiosa, parece desfrutar de uma liberdade "sem lei" resultante da sua exposição à aleatoriedade dos acontecimentos históricos e das decisões pessoais cuja origem reside na própria liberdade.

O problema da contingência - e da possibilidade de liberdade que lhe está associada -, bem como o modo de lidar com esse mesmo problema é aquilo que simultaneamente aproxima Arendt de Hegel e a afasta dele.

A aproximação justifica-se porque ambos tentam lidar com o problema da contingência, a partir da situação herdada de Kant, atribuindo uma relevância central ao reino dos assuntos humanos, relevância que lhe estava tradicionalmente vedada na filosofia. Assim, a interlocução da filosofia com a história, bem como a noção de historicidade do ser humano, são traços comuns às abordagens de filosofia política de Hegel e de Arendt, cada um a partir de seus respectivos contextos directos, mas ambos com uma visão em perspectiva das correspondências entre a história mundial, as ideias e os conceitos.

24 Arendt, Essays in Understanding: 1930-1954 Formation, Exile, and Totalitarianism, 168.

25 Arendt, "The Spiritual Quest of Modern Man_The Answer of the Existentialists."

\begin{tabular}{|l|l|l|l|l|}
\hline Q Povista 2 Dialectus & Ano 5 & n. 12 & Janeiro - Julho 2018 & p. 374-399 \\
\hline
\end{tabular}


Foi determinante para a atitude de ambos para com os assuntos humanos o facto de terem vivido em momentos particularmente significativos do ponto de vista histórico-político. Hegel pôde observar e analisar directamente o Antigo Regime, a Revolução Industrial, a Revolução Francesa, o Terror, Napoleão, e a Restauração instaurada pelo Congresso de Viena. Já Arendt testemunhou as duas grandes guerras, o surgimento dos regimes totalitários, o Holocausto, a luta pelos direitos civis e a sociedade de consumo.

Hegel e Arendt têm ainda como preocupação comum evitar teorias puramente normativas e recusar posições somente descritivas, partilhando ainda uma sensibilidade especialmente afinada para os modos de doação de uma certa universalidade na particularidade dos fenómenos histórico-políticos. Isso resulta numa atenção à política que tem como base uma acção performativa caracterizada pela capacidade de trazer à existência e sustentar na existência uma dimensão do ser propriamente humana que exige dos seus integrantes uma constituição de sentido amparada na sua condição de singulares que coexistem num mesmo mundo, numa mesma ordem de significações.

Um outro ponto de aproximação é o facto de não entenderem a liberdade como ausência de impedimentos para cada um fazer o que quer, mas como a faculdade de se dar as próprias leis ou condições através de acções realizadas no espaço público; esse é um legado recebido por ambos da política grega.

Mas também se justifica o seu afastamento porque a posição de Hegel constitui, para Arendt, um retorno ao postulado da identidade entre Pensar e Ser e, consequentemente, um retorno à metafísica. Este retorno tem lugar por via do olhar retrospectivo do filósofo, cujo pensar pode apropriar-se e recolher a significância e a necessidade do movimento histórico e do seu desenvolvimento temporal, preservando aquilo que na realidade aparece retrospectivamente como necessário e purificando-a com respeito ao meramente acidental. Subjacente a isso está uma filosofia da história assente numa ideia de razão e de sentido que se escondem no curso aparentemente aleatório dos acontecimentos do mundo e que regem a contingência das vontades humanas, dirigindo-as para uma meta que nunca foi por elas visada e assim reconciliando Mente e Mundo, Pensar e $\operatorname{Ser}^{26}$.

26 Hannah Arendt, «Willing» in The Life of the Mind (New York: Harcourt Brace Jovanovich, 1978), 28.

\begin{tabular}{|l|l|l|l|l|}
\hline Q Povista Dialectus & Ano 5 & n. 12 & Janeiro - Julho 2018 & p. 374-399 \\
\hline
\end{tabular}


O ponto de vista hegeliano não é o de uma análise conjuntural, mas aquele que procura elevar essa realidade recém-descoberta à dignidade do próprio conceito filosófico. A sua Filosofia do Direito constitui o exemplo paradigmático desse processo e dos princípios que governam a sua filosofia em geral. Nesse texto, Hegel apresenta sua versão mais detalhada do conceito de Estado, inserindo-se não somente no contexto dos debates políticos e sociais de seu tempo, mas supondo o horizonte mais amplo da reflexão filosófica: trata-se, portanto, não de uma obra apenas política, mas fundamentalmente de filosofia política ${ }^{27}$. Não se nega nela a historicidade dos conceitos, mas tampouco se reduz a filosofia ao contexto histórico.

No âmbito interno do hegelianismo, podemos compreender essa tese com base no conceito lógico de "realidade efetiva" ou "efetividade" (Wirklichkeit) e sua ampliação na definição do conceito de Estado. É notável a insistência com a qual Hegel começa seu tratamento do Estado na Filosofia do Direito exigindo que o leitor se localize aqui ao nível da efetividade do Estado: ele é a realidade efetiva da ideia ética ( $\$$ 257), da vontade substancial ( $§ 258)$, da liberdade concreta ( $(260)$. E o que é ser uma realidade efetiva? Inicialmente é ser uma realidade, isto é, não se trata aqui da enunciação de uma pura normatividade conceitual ou teórica. Porém, não é ser qualquer realidade empírica, mas aquelas que correspondem ao conceito, ou seja, que expressam padrões de racionalidade exemplares em seu funcionamento concreto, em sua concepção de si mesma e em suas práticas.

E é esta recondução da realidade ao conceito - ao processo de pensamento em nome da sua efectividade que se revela problemática para Arendt, uma vez que ela parece aniquilar precisamente aquilo de que se propunha dar conta: a contingência e a possibilidade da emergência do novo.

De facto, a descoberta de um domínio do Ser marcado pela contingência, pela liberdade humana e pela possibilidade do novo colocou Kant perante uma perplexidade: o poder de começar espontaneamente uma nova série de estados de coisas tem um começo absoluto no acontecimento que constitui esse mesmo começo; não obstante, esse mesmo acontecimento continua apenas a sucessão de estados de coisas que o precedeu.

27 Jean-François Kervégan, "Introduction: l'institution de la liberté," Principes de la philosophie du droit (Paris: Presses Universitaires de France, 2013), 18.

\begin{tabular}{|l|l|l|l|l|}
\hline Q Povista Qialectus & Ano 5 & n. 12 & Janeiro - Julho 2018 & p. 374-399 \\
\hline
\end{tabular}


A solução tradicional para esta perplexidade - e aquela que Hegel parece ter adoptado e desenvolvido a seu modo próprio - tem origem na distinção traçada por Aristóteles entre potencialidade e actualidade, assumindo-se que a nova série estava potencialmente contida na série que a precedeu.

Mas Arendt considera que a explicação de Aristóteles é insuficiente pois «pode alguém seriamente sustentar que a sinfonia produzida por um compositor era possível antes de ser actual? - a não ser que com "possível” não queiramos dizer mais do que não era claramente impossível, o que, claro está, é inteiramente diferente de ter existido num estado de potencialidade à espera de algum músico que se desse ao trabalho de a actualizar) $\gg^{28}$. Isto implicaria a redução da capacidade de começar de novo a uma escolha entre possibilidades já dadas como potencialidades de ser, consequentemente anulando a possibilidade de emergência do novo como tal.

Apropriando-se de Bergson, Arendt dirá que a maioria dos filósofos tem dificuldades em lidar com a novidade radical, reduzindo a liberdade a uma escolha entre opções dadas - isto é, passadas - sob a forma de possibilidades que se projectam no futuro, assim abolindo o futuro por via da sua assimilação ao passado e à antiga ordem de $\operatorname{coisas}^{29}$.

Deste modo, para Arendt, a preservação do poder de começar de novo bem como da imprevisibilidade que o acompanha - exige que este mesmo poder não seja precedido por qualquer potencialidade que possa ser tomada como a causa do acto que nele se efectiva.

Começam assim a revelar-se as reservas e mesmo uma certa ambiguidade de Arendt relativamente à filosofia hegeliana da história, a qual é, não obstante, impossível de evitar. Segundo Arendt:

[...] Hegel forneceu uma explicação filosófica para todos os fenómenos da natureza e da história e reuniu-os num todo estranhamente unificado. A sua filosofia, da qual ninguém pôde alguma vez estar bem seguro se fornecia uma residência ou uma prisão para a realidade, foi verdadeiramente "a coruja de Minerva que levanta voo apenas no crepúsculo". Imediatamente após a morte de Hegel, tornou-se aparente que o seu sistema representava a última palavra de toda a filosofia ocidental, pelo menos na medida em que, desde Parménides, ela não tinha - mesmo com todas as suas diversas viradas e aparentes contradições internas - alguma vez ousado colocar em questão a unidade de pensamento e Ser: to gar auto esti noein te kai einai. Aqueles que vieram depois de Hegel ou seguiram as suas pisadas ou se rebelaram contra

28 Arendt, «Willing» in The Life of the Mind, 1978, 30.

29 Arendt, «Willing» in The Life of the Mind, 1978, 32.

\begin{tabular}{|l|l|l|l|l|}
\hline Revista Dialectus & Ano 5 & n. 12 & Janeiro - Julho 2018 & p. 374-399 \\
\hline
\end{tabular}


ele, e aquilo contra o qual se rebelaram, e desesperavam, era a própria filosofia, a identidade postulada entre pensamento e Ser. ${ }^{30}$

A relação entre o conceito filosófico e a efectividade histórica veio a ser subsumida no molde de uma filosofia da história articuladora da identidade entre o pensar racional e o ser aí do mundo. A filosofia hegeliana da história constitui, portanto, uma espécie de compreensão preliminar do mundo contemporâneo, uma compreensão preliminar com que aqueles que o seguiram têm de lidar e cujos limites têm de ser postos à prova para que a possibilidade de novidade radical seja preservada.

\section{SER E TEMPORALIDADE: Hegel E ARENDT ENTRE O PASSADO E O FUTURO}

A posição de Arendt fica mais clara acompanhando a sua análise do carácter paradoxal do tempo na filosofia da história de Hegel, um pensador cuja originalidade, segundo Koyré $^{31}$, reside na primazia do futuro sobre o passado e na confiança no Progresso, ao mesmo tempo que, para Arendt, se constitui como o primeiro pensador a conceber uma filosofia da história, isto é, uma filosofia do passado. Para ilustrar essa perplexidade inerente à posição hegeliana, Arendt afirma:

[...] o próprio Hegel disse que "todos são filhos do seu próprio tempo, e consequentemente a filosofia é o seu tempo compreendido no pensamento". Mas ele também disse, no mesmo contexto, que "a tarefa da filosofia é compreender aquilo que existe, pois aquilo que existe é razão", ou "aquilo que é pensado é, e aquilo que é existe apenas na medida em que é pensado". E é sobre esta premissa que se baseia a mais importante e mais influente contribuição de Hegel para a filosofia. ${ }^{32}$

Para compreendermos melhor o modo como Arendt concebe esta suposta contradição interna ao sistema filosófico hegeliano é necessário que atendamos à sua concepção de temporalidade e à sua interpretação da temporalidade em Hegel, o que implica atender às diferenças nos modos de conceber a relação entre os diferentes modos dessa mesma temporalidade.

Referimos anteriormente que, para Arendt, a filosofia tem de lidar com facto das coisas existirem sem razão, ou seja, a filosofia tem de lidar com o facto da contingência e da concomitante ausência de fundamento de tudo aquilo que é. Uma vez que essa ausência ou inessência (Abwesenheit) veio ao ser com a inserção do humano no

30 Arendt, Essays in Understanding: 1930-1954 Formation, Exile, and Totalitarianism, 164.

31 Arendt, «Willing» in The Life of the Mind, 1978, 40.

32 Arendt, «Willing» in The Life of the Mind, 1978, 40.

\begin{tabular}{|l|l|l|l|l|}
\hline Revista Qialectus & Ano 5 & n. 12 & Janeiro - Julho 2018 & p. 374-399 \\
\hline
\end{tabular}


mundo, o humano torna presente essa ausência através da sua relação com o seu ser. Esta relação do humano com o seu próprio ser constitui, no quadro do pensamento arendtiano, a vida da mente, cuja «[...] única manifestação exterior [...] é o alheamento [absentmindedness], uma óbvia falta de atenção para com o mundo circundante, algo meramente negativo que não indicia o que acontece em nós» ${ }^{33}$. Aquilo que é experienciado no mundo como falta de um ser próprio ou inessencialidade não é mais do que a própria vida da mente, a qual tem como traço a invisibilidade.

A inessencialidade ou ausência que manifesta em tudo aquilo que existe é trazida à presença pelas actividades mentais justamente enquanto ausência, assim notificando o humano da possibilidade de ser em sentido próprio sem recorrer a essências ou fundamentos dados. Na vida da mente, é a própria possibilidade da liberdade humana e da capacidade de começar de novo que renovam o seu sentido, justamente acolhendo o carácter contingente e abismal da existência. Pensar é, para Arendt, uma actualização da necessidade de razão, da experiência da falta de um ser próprio ou essência que, paradoxalmente, intensifica e reafirma a possibilidade de ser humano. Não é por acaso que Arendt coloca a questão "O que nos faz pensar?" no centro das suas reflexões, apresentando como resposta: a demanda pelo sentido, uma vez que é esta demanda por sentido - e não um qualquer sentido específico dado e actualizado - que actualiza o abismo do presente, o carácter infundado de tudo aquilo que é e, consequentemente, renova o sentido da própria existência e do seu carácter contingente.

A tradução deste posicionamento na concepção arendtiana de tempo tem lugar na sua apropriação de uma parábola de Kafka, a qual é simultaneamente uma experiência de pensamento:

Ele tem dois antagonistas: o primeiro pressiona-o a partir de trás, a partir da origem. O segundo bloqueia a estrada adiante. Ele batalha com ambos. É certo que o primeiro o apoia no seu combate com o segundo, pois quer empurra-lo para a frente, e do mesmo modo o segundo apoia-o no seu combate com o primeiro, uma vez que o impele para trás. Mas isto é assim apenas teoricamente. Pois não são apenas dois antagonistas que ali estão, mas também ele mesmo, e quem conhece realmente as suas intenções? O seu sonho, contudo, é que um dia, num momento não-vigiado - e isto exigiria uma noite mais escura do que qualquer noite que alguma vez tenha sido - ele salte para fora da linha de combate e seja promovido, por conta da sua

33 Arendt, «Thinking» in The Life of the Mind, 1978, 72.

\begin{tabular}{|c|c|c|c|c|}
\hline Rovista Dialectus & Ano 5 & n. 12 & Janeiro - Julho 2018 & p. $374-399$ \\
\hline
\end{tabular}


experiência em combate, à posição de árbitro sobre os seus antagonistas no seu combate um com o outro. ${ }^{34}$

Nesta parábola, passado e futuro são forças entre as quais se interpõe um terceiro, o qual constitui um elemento teoricamente mediador e é referido sempre na terceira pessoa, como se a sua fosse uma presença que manifestasse, paradoxalmente, pela sua ausência. O ser do humano sustém-se entre passado - não-mais - e futuro ainda-não - como um abismo, um intervalo conservado apenas em virtude do seu esforço agónico.

Arendt introduz uma pequena diferença nesta experiência de pensamento.

Na versão de Kafka, o modo como este abismo se interpõe na sucessão, criando o fluxo do tempo, assume contornos tradicionais, de acordo com os quais a temporalidade corresponde a um movimento rectilíneo no qual praticamente não existe espaço para "Ele" se suster. A direccionalidade - o "sentido" - conferida ao contínuo temporal está sempre dependente de uma medida do tempo que sempre está ou aspira a estar fora do tempo. Segundo Arendt, sempre que

[...] "ele" pensa em dispor-se vigorosamente por si mesmo, "ele" cai numa região sobre e acima da linha de combate, e que outra coisa é este sonho e esta região senão o velho sonho que a metafísica ocidental sonhou de Parménides a Hegel de um reino supra-sensível sem tempo, sem espaço, como a região própria do pensamento $?^{35}$

A destruição da identidade tradicional entre Pensar e Ser decretou o fim deste modo de pensar a constituição de tudo aquilo que é, um modo de pensar que parte de uma perspectiva absolutamente desvinculada do mundo e da temporalidade, assim determinando uma putativa superioridade ontológica da essência relativamente à existência. Permanecendo vinculada à perspectiva da tradição, a descrição de Kafka carece de uma dimensão espacial, de uma dimensão na qual o pensar possa ser propriamente exercido e a temporalidade descubra algum tipo de medida sem que isso signifique um salto para a intemporalidade.

Já para Arendt, a inserção do humano na temporalidade cria um ponto de deflexão, desviando e orientando as forças do passado e do futuro e assim resultando num espaço que não é um simples intervalo no tempo, embora fora do tempo, mas uma

${ }^{34}$ Hannah Arendt, Between Past and Future: Eight Exercises in Political Thought (New York: Viking Press, 2006), 9.

35 Ibid., 11.

\begin{tabular}{|l|l|l|l|l|}
\hline Q Rovista Dialectus & Ano 5 & n. 12 & Janeiro - Julho 2018 & p. 374-399 \\
\hline
\end{tabular}


dimensão de densidade que «se assemelha àquilo a que os físicos chamam um paralelograma de forças ${ }^{36}$ e que serve de medida da temporalidade na e a partir da própria temporalidade. Esse espaço constitui o "lugar" próprio do "terceiro", dessa ausência ou inessencialidade que constitui o tema e a mediação de tudo aquilo que é, particularmente tudo aquilo que é trazido à existência por feitos e por palavras, isto é, constitui o próprio mundo, o qual adquire assim não só uma nova dignidade ontológica, mas se torna também o referencial da existência: o humano não é apenas ser-no-mundo, descobrindo o seu ser mais próprio para lá do mundo; o humano é mais radical e propriamente ser-do-mundo, pertencendo-lhe essencialmente.

A inserção do "terceiro" no campo de batalha no qual se encontram as duas forças antagónicas de passado e futuro resulta numa terceira força, uma força que se projecta na diagonal e cuja origem é o ponto de encontro e de acção das restantes forças. Sendo ambas provenientes de um infinito, nenhuma das forças tem um começo, apenas um ponto terminal. Este ponto terminal constitui a origem da terceira força, a qual não tem qualquer fim. Mas possui uma origem ou começo, um referencial a que se pode regressar retrospectivamente, assim constituindo um passado, e a partir do qual se pode projectivamente antecipar um futuro. Citando Agostinho, Arendt dirá:

\footnotetext{
"Initium ut esset homo creatus est ante quem nemo fuit". "O homem foi criado para que houvesse um começo”, o que ligaria a acção, a capacidade de começar, ao facto de todo o ser humano ser já, por natureza, um novo começo que nunca antes apareceu ou foi visto no mundo. ${ }^{37}$
}

No entanto, esta é, para Arendt, apenas uma experiência de pensamento que tem lugar no reino dos fenómenos mentais e não na plena actualidade de seres concretos. Ou seja, esta é apenas uma possibilidade cuja concretização não tem quaisquer garantias, a possibilidade da descoberta da liberdade e de si mesmo como livre. $\mathrm{Na}$ verdade, a experiência existencial mais imediata e constante é a do esquecimento desta possibilidade de começar, esquecimento que dá notícia de si no interior do mundo sob a forma de uma falta de ser próprio que se manifesta no reino social e no correspondente processo de produção e consumo de necessidades. Por essa razão, este "terceiro" que vive no abismo entre o passado e o futuro não é um "alguém"

\footnotetext{
36 Ibid.

37 Hannah Arendt, The Promise of Politics, ed. Jerome Kohn (New York: Schocken Books, 2005), 59.

\begin{tabular}{|c|c|c|c|c|}
\hline Rovista Aialectus & Ano 5 & n. 12 & Janeiro - Julho 2018 & p. 374-399 \\
\hline
\end{tabular}
}


afectado pela ruína própria do tempo histórico e biográfico. Ou seja, a existência não é idêntica à essência, Ser não é Pensar:

É humano agir e querer agir; é humano pensar e querer pensar. Onde quer que não os tenham combinados no homem vivo, embora sejam em certo sentido opostos, têm ou acção impensada ou pensamento impotente. É sempre a vida que oferece as soluções. ${ }^{38}$

A identidade entre Ser e Pensar implicaria, para Arendt, que a direccionalidade ou medida da temporalidade e, por extensão, dos assuntos humanos e do próprio mundo estaria sempre já necessariamente dada, bastando a cada um aplicá-la, isto é, torná-la efectiva.

Embora Arendt partilhe com Hegel a tentativa de atribuição de uma nova dignidade ontológica ao reino dos assuntos humanos, marcados pela contingência, uma comparação das respectivas concepções de temporalidade torna evidente a sua divergência central, esta identidade entre Ser e Pensar e a sua consequência imediata, a reintrodução da necessidade no reino dos assuntos humanos por intermédio de uma filosofia da história.

Referimos já que Arendt considera Hegel o primeiro pensador a conceber uma filosofia da história, isto é, uma filosofia do passado: o passado é apropriado pela mente através do esforço do conceito e neste esforço de apropriação ocorre a reconciliação de mente e de mundo, de Pensar e de Ser.

Seguindo a linha interpretativa proposta por Koyré, Arendt afirma que esta prioridade do passado desaparece quando Hegel trata da questão da temporalidade. Na leitura que Arendt faz da posição de Hegel, o tempo é primeiro experienciado pelo humano como pura moção e de modo impensado e alheado (absentminded) até que ocorre algum tipo de reflexão sobre o sentido dos acontecimentos exteriores. Na medida em que o tempo está já em curso antes de qualquer reflexão a respeito do seu sentido, antecipando-se a ela, toda a reflexão é dirigida a um tempo que vem na nossa direcção, isto é, a um tempo porvir - o futuro.

O futuro antecipado nega o presente da mente, o qual é antecipado como um não-mais, como um passado. Assim, embora seja o futuro e a sua capacidade de negar o

38 Hannah Arendt, "Philosophy and Politics. What is Political Philosophy? Lectures and Seminar," Hannah Arendt Papers at the Library of Congress, 1969, http://memory.loc.gov/cgibin/ampage collId=mharendt $\&$ fileName $=04 / 040460 / 040460$ page $. \mathrm{db} \& \mathrm{recNum}=0$.

\begin{tabular}{|l|l|l|l|l|}
\hline Qevista Dialectus & Ano 5 & n. 12 & Janeiro - Julho 2018 & p. 374-399 \\
\hline
\end{tabular}


presente que cumpre o Ser, este pertence ao passado na sua qualidade de ser-cumprido ou ser-sido, isto é, de essência. Determinado por um ser que se cumpre no futuro, a essência do presente é ausência, é não-ser, um vazio que se preenche e que descobre realidade num futuro que está nele sempre já contido como o seu facto negativo. E a mente, referida a si mesma e à sua própria actividade, consiste numa transformação contínua do seu próprio futuro num presente - num não-ser -, deixando de ser quando o futuro se cumpriu.

No entanto, esta perda de futuro coincide com o cumprimento da vida individual, a qual escapa à mudança e à imprevisibilidade do futuro através da retrospecção, assim se abrindo à quietude do passado, ou seja, do ser-sido ou essência. Isto ocorre quando a processualidade na qual o Ser se desdobra e se desenvolve é interrompida e atinge um fim. Segundo Arendt, «“a intranquilidade é o solo do Ser”, é o preço pago pela Vida, tal como a morte ou, antes, a antecipação da morte, é o preço pago pela tranquilidade ${ }^{39}$.

Na perspectiva de Arendt, Hegel considera que a intranquilidade dos vivos e, como tal, a ausência de fundamento e a correspondente contingência - não resulta do movimento incessante daquilo que é dado e da imprevisibilidade dos destinos humanos, mas está localizada na mente humana e é por ela engendrada. Na medida em que a mente humana, no processo de constituição de si, constitui a distensão temporal, o ser humano não é apenas no tempo, ele é Tempo. A temporalidade é a essência do humano. É porque a mente humana produz o tempo, capacitando assim o ser humano a ter noção de que um dia veio à existência e de que um dia deixará de existir, que este pode antecipar a morte - o seu fim derradeiro - como a frustração de todos os seus projectos futuros:

\footnotetext{
Em Hegel, o homem não se distingue das outras espécies animais por ser um animal rationale, mas por ser a única criatura viva que sabe acerca da sua própria morte. [...] e é neste sentido que Hegel mantém que apenas a mente que "não ignora a morte" capacita o homem a "dominar a morte", a "suportála e a manter-se no seu interior". 40
}

É quando a mente se confronta reflexivamente com o seu próprio fim que a dialéctica temporal é interrompida e o tempo se cumpre, declinando-se num ser-sido ou

39 Arendt, «Willing» in The Life of the Mind, 1978, 42.

40 Ibid., 43.

\begin{tabular}{|l|l|l|l|l|}
\hline Q Rovista Dialectus & Ano 5 & n. 12 & Janeiro - Julho 2018 & p. 374-399 \\
\hline
\end{tabular}


essência - num passado - no qual o futuro se tornou completamente presente e para o qual o Ser não é mais uma possibilidade e, portanto, essencialmente contingente, mas antes um movimento necessário da própria mente que balança agora sobre si mesmo e assim se concebe como fundamento eterno de tudo aquilo que é. Resumidamente, parece que o verdadeiro Ser do futuro - e do humano - é não-ser, é a própria negatividade constitutiva do movimento de produção de possibilidades de ser e, portanto, da liberdade. Por outras palavras, o verdadeiro ser do futuro é o Agora, o presente, desta vez compreendido não como um mero momento particular, mas como o movimento da própria mente que reúne e recolhe em si mesma passado, presente e futuro $^{41}$, um movimento eterno - necessário, paradoxalmente imutável e sempre totalmente presente - que permite à mente «intuir e conceptualizar todo o ciclo do Devir» ${ }^{42}$.

\section{HANNAH ARENDT E O HEGELIANISMO METAFíSICO}

É com base neste ponto que se articula a crítica de Arendt à teleologia que reduz todos os acontecimentos à lei da processualidade histórica tal como ela se compreende a partir da sua interpretação da concepção hegeliana de tempo, reintroduzindo a primazia tradicional da necessidade na recém-dignificada contingência do reino dos assuntos humanos.

É igualmente aqui que está radicada a crítica arendtiana à fé dogmática no Progresso como projecto de humanidade. Segundo Arendt, «[...] a noção de progresso do séc. XVIII, tal como concebida na França pré-revolucionária, pretendia que a crítica do passado fosse um meio de dominar o presente e de controlar o futuro; o progresso culminou na emancipação do homem ${ }^{43}$.

Como se sabe, o catalisador da mudança de atitude na filosofia, protagonizada por Hegel, para com a história e a sua sucessão baseada em acasos e decisões pessoais aleatórias, aparentemente desprovida de fundamentos racionais e imprevisível nas suas metas, foi a Revolução Francesa. A proclamação dos Direitos do

${ }^{41}$ Ibid., 43-44.

${ }^{42}$ Ibid., 49.

43 Hannah Arendt, The Origins of Totalitarianism. New Edition with Added Prefaces. (New York: Harcourt Brace Jovanovich, 1973), 143.

\begin{tabular}{|l|l|l|l|l|}
\hline Gevista Qialectus & Ano 5 & n. 12 & Janeiro - Julho 2018 & p. 374-399 \\
\hline
\end{tabular}


Homem marcou o momento da emancipação do ser humano relativamente a toda a tutela e o anúncio da sua chegada à maioridade, isto é, a afirmação da sua autonomia ${ }^{44}$.

Como já referimos, Arendt considera que o tempo, na perspectiva de Hegel, é produzido pela mente, sendo essa a base da sua identificação entre lógica compreendida simultaneamente como ontologia ou filosofia primeira e estrutura discursivo-categorial a priori do pensamento, implícitas à mente humana - e história o lugar do seu desdobramento e explicitação. Nem sempre esse é o caso, mas é nos momentos de viragem política que, no quadro do sistema hegeliano, o pensamento se antecipa à realidade e a enforma.

De acordo com essa premissa, a Revolução Francesa foi a primeira vez em que o ser humano se atreveu a sustentar-se sobre a sua cabeça e pensamento, construindo a realidade através da instituição de uma ordem de múltiplas relações que tem a sua reivindicação de autonomia como referencial máximo e que o institui como referencial normativo. A Revolução Francesa foi o momento de reconciliação entre o princípio eterno de movimento no qual o ser humano passa o tempo em que ele próprio se constitui e a contingência e imprevisibilidade dos assuntos humanos.

Na medida em que esta reconciliação se estabelece como o núcleo do sistema hegeliano, ela torna possível uma compreensão da história como uma sucessão de acontecimentos que descobrem o seu desfecho na incorporação do reino mental no reino secular, conferindo um fundamento e uma direccionalidade aos assuntos humanos, assim anulando o seu carácter fortuito e desprovido de sentido.

A consequência desta tentativa de reconciliação é a interpretação da sucessão histórica como um processo de desvelamento da verdade, um processo pelo qual o humano devém humano e que é tarefa da filosofia compreender desde a sua origem escondida até à sua manifestação presente. Ou seja, a reconciliação filosófica, sustentada no princípio eterno de movimento estabelecido no espírito humano como o princípio ordenador da própria realidade e aplicando-o retrospectivamente, deve conduzir à perspectiva de que o mundo é tal como deve ser.

Para Arendt, a aparente perda de contingência por parte dos factos e o seu recobrimento sob a capa da necessidade - em suma, a identificação da liberdade com a

${ }^{44}$ Para uma exploração do significado político-existencial desta proclamação, veja-se Nuno Pereira Castanheira, "Hannah Arendt, Estado-Nação e Imperialismo: Prolegómeno a uma Crítica Arendtiana dos Direitos do Homem," in Actas Das Jornadas de Jovens Investigadores de Filosofia (Évora: Krisis, 2010), 281-93.

\begin{tabular}{|l|l|l|l|l|}
\hline Q Povista Qialectus & Ano 5 & n. 12 & Janeiro - Julho 2018 & p. 374-399 \\
\hline
\end{tabular}


necessidade e daquilo que é com aquilo que tinha de ser - é um efeito da retrospecção, a qual tem de considerar tudo aquilo que deve a sua origem à liberdade como facto cumprido constitutivo da realidade.

Deste ponto de vista, a necessidade parece ser uma ilusão, uma ilusão que esconde o facto de "contingente" significar apenas que as coisas poderiam ter sido de outro modo, que os acontecimentos são verdades factuais cujo oposto não é inconcebível, e não que as coisas existiam num estado de potencialidade aguardando efectivação. Diz Arendt:

De acordo com Hegel, a mente, pela pura força da reflexão, pode assimilar a si mesma - sugar para si mesma, por assim dizer - não, seguramente, todos os aparecimentos, mas o que quer que foi neles significativo, deixando de lado todo o não assimilável como um acidente irrelevante, sem consequência quer para o curso da História, quer para o curso do pensamento discursivo. ${ }^{45}$

Assim, do ponto de vista de Arendt, a reconciliação hegeliana só seria possível se a Revolução Francesa constituísse efectivamente o princípio do fim da história, o momento em que a história se completou e em que a realidade foi purificada pelo Ser autêntico, o qual é idêntico ao Pensar. Seria apenas sob a condição essencial do fim factual da história e, consequentemente, sob condição de não restar mais futuro à humanidade - no sentido de se ter cumprido e de nada de radicalmente novo poder já acontecer - que se tornaria possível a Hegel reivindicar, de acordo com Arendt, uma verdade objectiva para a sua posição filosófica.

Esta posição não seria compatível com a noção de Progresso, uma vez esta está ancorada numa noção rectilínea de tempo e não num tempo cíclico - e este é o único tempo que se coaduna com a exigência de eternidade, mesmo que esta seja concebida como devir - no qual o começo ou momento da geração é pressuposto e atingido plenamente no seu fim, isto é, um tempo que se compreende como actualização de potencialidades dadas que, por via dessa mesma actualização, regressam a si mesmas, ao ser que é verdadeiramente o seu.

Para dar conta da contradição entre esta noção de cíclica de tempo com a noção de Progresso, dependente de uma noção rectilínea de tempo, Hegel presume a existência de um movimento que atravessa e transcende as gerações particulares, os seres humanos individuais e de nações particulares, um movimento dialéctico que

45 Arendt, «Willing» in The Life of the Mind, 1978, 40.

\begin{tabular}{|c|c|c|c|c|}
\hline Q Rovista Dialeatus & Ano 5 & n. 12 & Janeiro - Julho 2018 & p. $374-399$ \\
\hline
\end{tabular}


garante um progresso infinito e que é uma presença cujo corpo é a própria Humanidade e a que Hegel chama Espírito do Mundo - uma Mente Mundial, diz Arendt, para mandar «sobre a pluralidade das vontades humanas e dirigi-las para a "plenitude de sentido" que brota da necessidade da razão, isto é, psicologicamente falando, brotando do desejo muito humano de viver num mundo que é tal como deve ser» ${ }^{46}$.

Mas esta é apenas uma hipótese que escapa a toda a experiência e que assenta no pressuposto de apodicticidade, de auto-evidência de um Ser que, pelo contrário, é tudo menos garantido e que tem de estar sempre hipoteticamente presente como condição de possibilidade de sentido daquilo que é, de outro modo, em si mesmo e factualmente, insignificante e contingente, a saber, a existência deste ou daquele ser humano, a qual precede o pensamento da humanidade e do seu putativo progresso. A experiência do próprio pensar mostra que não há movimento dialéctico que comece a partir do não-ser pois toda a negação tem de negar algo específico e particular - do nãoser nada devém. Desse modo, todo o ser está já contido no começo, restando apenas o seu necessário desvelamento no tempo, isto é, no ser humano particular que não é senão função de produção de um projecto de humanidade dado à partida e que opera nas suas costas. E é esta hipótese, marcadamente metafísica, que Hegel põe na base do seu sistema e parece deixar por questionar.

Este ponto sublinha, uma vez mais, o carácter fundado e, consequentemente, antepredicativamente dado do Ser - o Ser não é um predicado da essência, Ser não é idêntico a Pensar -, desvelando o propósito meramente funcional deste conceito personificado que se articula no Espírito do Mundo, «[...] esse Ninguém fantasmagórico $[\ldots]{ }^{47}$ : explicar e justificar o ser como dado, ou seja, encobrir a contingência fundamental de tudo aquilo que é sob a capa de uma necessidade processual de cariz metafísico que garanta que a força do negativo - a força desencadeada pela própria liberdade humana - resulta num Progresso infinito, quando é bem claro que nada impede que resulte, ao invés, num processo de permanente aniquilação. Pergunta Arendt, aludindo à imprevisibilidade inerente à liberdade humana, à sua capacidade de começar e à contingência da própria existência, bem como à responsabilidade política do filósofo perante acontecimentos sem precedentes:

46 Ibid., 49.

47 Ibid., 187.

\begin{tabular}{|l|l|l|l|l|}
\hline Qevista Qialectus & Ano 5 & n. 12 & Janeiro - Julho 2018 & p. 374-399 \\
\hline
\end{tabular}


Quem se atreveria a reconciliar-se com a realidade dos campos de extermínio ou a jogar o jogo da tese-antítese-síntese até que a sua dialéctica tivesse descoberto "sentido" no trabalho escravo? [...] Parece-me característico que nenhum dos filósofos tenha mencionado ou analisado em termos filosóficos este pano de fundo da experiência. É como se nesta recusa em admitir a experiência do horror e em tomá-la seriamente, os filósofos tivessem herdado a tradicional recusa de conceder ao reino dos assuntos humanos aquele thaumazein, aquela admiração ante aquilo que é como é, que, de acordo com Platão e Aristóteles, está no começo de toda a filosofia, mas que contudo até eles recusaram aceitar como a condição preliminar da filosofia política. Pois o horror mudo ante aquilo que o homem pode fazer e aquilo em que o mundo pode tornar-se está, de muitas maneiras, relacionado com a admiração muda de gratidão a partir da qual brotam as questões da filosofia. ${ }^{48}$

\section{CONCLUSÃo}

Uma das características fundamentais da filosofia prática de Hegel reside no estabelecimento de uma relação intrínseca entre o conceito filosófico e seu tempo histórico. Essa relação é parcialmente apropriada pelo pensamento político de Arendt, a partir de uma perspectiva não transcendentalista da filosofia frente ao mundo.

No entanto, Arendt não segue o sistema hegeliano em derivar daquela relação uma filosofia da história amparada pela busca de um sentido para o conjunto das criações humanas. Em outras palavras, não há para ela uma totalização possível para as obras do espírito. Ou seja, Arendt critica o fundo lógico-metafísico da teoria hegeliana do espírito objetivo, amparado na produção de uma identidade entre o Pensar e o Ser.

Nesse quadro, Arendt portanto não rejeita em bloco o sistema hegeliano, mas tampouco o adopta integralmente. Pode-se assim afirmar que Arendt antecipa uma linha hermenêutica actualmente em voga nos estudos hegelianos, o hegelianismo pósmetafísico $^{49}$.

A diferença decisiva entre a posição de Arendt e a de Hegel no que à história diz respeito deixa-se captar numa distinção sublinhada pela pensadora num texto sobre Walter Benjamin, a distinção entre alegoria e metáfora ${ }^{50}$.

Para Arendt, as alegorias têm origem em noções abstractas - ideias - e representam essas noções do modo que lhes é mais conveniente, isto é, do modo que mais se adequa à concepção de ser que pressupõem e tomam por evidente, necessária e absolutamente certa. Em face de um paradoxo - e o facto de a contingência ser o preço

48 Arendt, Essays in Understanding: 1930-1954 Formation, Exile, and Totalitarianism, 444-45.

49 Veja-se, a título de exemplo, Simon Lumsden, "The Rise of the Non-Metaphysical Hegel," Philosophy Compass 3, no. 1 (2008): 51-65.

50 Hannah Arendt, Men in Dark Times. (New York: Harcourt, Brace \& World, 1968), 153-206. Para um maior desenvolvimento do tema da metáfora em Arendt e a sua relação com o pensar e com a linguagem, veja-se Arendt, «Thinking» in The Life of the Mind, 1978, 99-125.

\begin{tabular}{|l|l|l|l|l|}
\hline Q Povista 2 Dialectus & Ano 5 & n. 12 & Janeiro - Julho 2018 & p. 374-399 \\
\hline
\end{tabular}


a pagar pela liberdade é o mais humano dos paradoxos -, a alegoria procura encontrar a uma solução, procura descobrir um fim e reduzir o paradoxo e a perplexidade que lhe está inerente a nada por via da explicação, do desdobramento e do desenvolvimento, até que o absurdo se torne significativo - pagando o preço de deixar de ser aquilo que é. $\mathrm{O}$ Espírito do Mundo é uma alegoria neste sentido.

A metáfora, por seu lado, estabelece um vínculo que é percebido no seu carácter imediato e que não exige interpretação, operando uma transferência entre a mente e as suas manifestações materiais por via da linguagem ${ }^{51}$. Não os conceitos ou as ideias, mas «as metáforas», diz Arendt, «são os meios pelos quais a unicidade do mundo é poeticamente trazida à existência» ${ }^{52}$, assim conferindo forma material ao invisível e tornando-o passível de ser experienciado sem necessidade de mediações. Esse é, para Arendt, o papel dos poetas e dos historiadores, resgatar do esquecimento - da falta de ser que se manifesta como necessidade - e preservar aquilo que deve a sua existência aos seres humanos. E isso significa aceitar e acolher a fragilidade, futilidade, imprevisibilidade e contingência do mundo que os próprios seres humanos constituíram a partir da liberdade que não é senão o fundamento da sua existência.

Referindo-se à posição de Jaspers a este respeito - uma posição que tem a sua origem na autonomia kantiana -, Arendt declara:

\begin{abstract}
Para Jaspers, a existência não é uma forma de Ser, mas uma forma da liberdade humana, a forma na qual "o homem, enquanto espontaneidade potencial, rejeita a concepção de si mesmo como mero resultado". A existência não é ser do homem enquanto tal e enquanto um dado; ao invés, "o homem é [...] existência possível". A palavra "existência" significa aqui que o homem alcança realidade apenas na medida em que age a partir da sua própria liberdade enraizada na espontaneidade, e "conecta-se com a liberdade de outros através da comunicação". ${ }^{53}$
\end{abstract}

Quer isto dizer que a factualidade contingente da existência não é a negação da liberdade humana, mas antes o horizonte a partir do qual a liberdade humana se diferencia e se concretiza como expressão última do paradoxo da liberdade:

51 Para uma resumida análise do sentido temporal destas correspondências e da sua influência em Arendt, veja-se Nuno Pereira Castanheira, "Estar em casa no mundo : Hannah Arendt, crise do sentido e ser do humano" (Faculdade de Letras da Universidade de Lisboa, 2015), 32-36, http://repositorio.ul.pt/handle/10451/19929.

52 Arendt, Men in Dark Times., 166.

53 Arendt, Essays in Understanding: 1930-1954 Formation, Exile, and Totalitarianism, 183.

\begin{tabular}{|l|l|l|l|l|}
\hline Q Rovista Qialectus & Ano 5 & n. 12 & Janeiro - Julho 2018 & p. 374-399 \\
\hline
\end{tabular}


É apenas por que não me fiz a mim mesmo que eu sou livre. Se eu me tivesse feito a mim mesmo, eu teria sido capaz de me prever a mim mesmo e, consequentemente, ter-me-ia tornado não-livre. ${ }^{54}$

Ou seja, é apenas por que o humano se experiencia como contingente, como condicionado por uma falta de ser - por uma ausência - que pode transcender os seus condicionamentos, que a liberdade se constitui em possibilidade real e o ser do humano num paradoxo vivo cuja resolução definitiva determinaria a aniquilação da humanidade no humano.

Nessa medida, se assumirmos um ponto de vista alegórico, o Progresso será apenas, como nos diz Benjamin no seu Sobre o Conceito de História ${ }^{55}$, uma tempestade que nos empurra inexorável e implacavelmente para um futuro que opera nas nossas costas e que deixa diante de nós, no passado, apenas um rasto de destruição, uma pilha de escombros, de ausências. Essa pilha de escombros é constituída pela pluralidade de existências prévias que agora se dispersam na insignificância e são votadas ao esquecimento pelo vento do Progresso.

Mas podemos olhar para o Progresso como uma metáfora - uma materialização da experiência do pensar na linguagem - e descobrir no pensar e na experiência de temporalidade que ele desvela - no abismo entre o passado e o futuro um modo de ir ao encontro dessas existências que preserva aquilo que elas têm de mais próprio - a própria ausência ou inessencialidade, o facto da sua contingência, o facto de existirem sem razão e a sua concomitante liberdade. Apropriando-se de um antigo verso latino - «A causa vitoriosa agrada aos deuses, mas a vencida agrada a Catão» ${ }^{56}$-, Arendt sugere que não neguemos a importância da história, mas que lhe neguemos o direito de ser o juiz derradeiro, preservando apenas o sentido daquilo que se adequa aos ditames inexoráveis dos seus processos. Talvez se renove assim a possibilidade de descobrirmos um modo de reunir a nossa própria existência, bem como o sentido, o tempo e a contingência que lhe são próprios, com essas outras existências cuja dignidade esteve ou está em risco, recolhendo-as num esforço de comunicação entre absolutamente diferentes que estabeleça entre nós um mundo - uma ordem de coexistência e de sentido - fundado na nossa livre constituição e que possa servir de

54 Ibid., 184.

55 Walter Benjamin, Gesammelte Schriften Bd. I, herausgegeben von Rolf Tiedemann und Hermann Schweppenhäuser (Frankfurt am Main: Suhrkamp, 1991), 697-98.

56 Hannah Arendt, Lectures on Kant's Political Philosophy / Hannah Arendt; Edited, and with an Interpretive Essay by Ronald Beiner, ed. Ronald Beiner (Chicago: University of Chicago Press, 1982).

\begin{tabular}{|l|l|l|l|l|}
\hline Revista Dialectus & Ano 5 & n. 12 & Janeiro - Julho 2018 & p. 374-399 \\
\hline
\end{tabular}


lugar de habitação para a «escumalha da Terra» ${ }^{57}$, para todos esses que a necessidade do Progresso e a sua lei sobre-humana excretam diariamente como factualmente insignificantes $^{58}$.

\section{REFERÊNCIAS}

Adler, Laure. Nos Passos de Hannah. Traduzido por Tatiana Salem Levy e Marcelo Jacques. Rio de Janeiro; São Paulo: Editora Record, 2007.

Arendt, Hannah. A Condição Humana. Traduzido por Roberto Raposo com revisão científica de Adriano Correia. 12 ${ }^{\mathrm{a}}$. Rio de Janeiro: Forense Universitária, 2014.

- Between Past and Future: Eight Exercises in Political Thought. New York: Viking Press, 2006.

- Between Past and Future: Eight Exercises in Political Thought. New York: Viking Press, 2006.

_. Essays in Understanding: 1930-1954 Formation, Exile, and Totalitarianism. Edited by Jerome Kohn. New York: Schocken Books, 1994.

- Lectures on Kant's Political Philosophy / Hannah Arendt ; Edited, and with an Interpretive Essay by Ronald Beiner. Edited by Ronald Beiner. Chicago:

University of Chicago Press, 1982.

—. Men in Dark Times. New York: Harcourt, Brace \& World, 1968.

_. "Philosophy and Politics. What is Political Philosophy? Lectures and Seminar."

Hannah Arendt Papers at the Library of Congress, 1969.

http://memory.loc.gov/cgi-

bin/ampage collId=mharendt\&fileName=04/040460/040460page $. \mathrm{db} \& \mathrm{recNum}=0$.

- The Human Condition. Chicago: University of Chicago Press, 1959.

- The Life of the Mind. Edited by Mary MacCarthy. One Volume. New York:

Harcourt, Inc., 1978.

- The Origins of Totalitarianism. New Edition with Added Prefaces. New York:

Harcourt Brace Jovanovich, 1973.

- The Promise of Politics. Edited by Jerome Kohn. New York: Schocken Books, 2005.

—. "The Spiritual Quest of Modern Man_The Answer of the Existentialists."

57 Arendt, The Origins of Totalitarianism. New Edition with Added Prefaces., 267.

58 Veja-se Hannah Arendt, Between Past and Future: Eight Exercises in Political Thought (New York: Viking Press, 2006), 41-90.

\begin{tabular}{|l|l|l|l|l|}
\hline Q Rovista Dialectus & Ano 5 & n. 12 & Janeiro - Julho 2018 & p. 374-399 \\
\hline
\end{tabular}


Hannah Arendt Papers at the Library of Congress, 1952.

http://memory.loc.gov/cgi-

bin/ampage collId=mharendt\&fileName=05/052280/052280page.$d b \&$ recNum=0.

Benjamin, Walter. Gesammelte Schriften Bd. I. Herausgegeben von Rolf Tiedemann

und Hermann Schweppenhäuser. Frankfurt am Main: Suhrkamp, 1991.

Castanheira, Nuno Pereira. "Estar em casa no mundo : Hannah Arendt, crise do sentido

e ser do humano." Faculdade de Letras da Universidade de Lisboa, 2015.

http://repositorio.ul.pt/handle/10451/19929.

—_. "Hannah Arendt, Estado-Nação e Imperialismo: Prolegómeno a uma Crítica

Arendtiana dos Direitos do Homem." In Actas Das Jornadas de Jovens

Investigadores de Filosofia, 281-93. Évora: Krisis, 2010.

Ferguson, Adam, and Fania Oz-Salzberger. An Essay on the History of Civil Society.

Cambridge: Cambridge University Press, 1995.

G.W.F. Hegel. Enzyklopädie der philosophischen Wissenschaften im Grundrisse (1830)

Gesammelte Werke 20. Herausgegeben von Wolfgang Bonsiepen und Hans

Christian Lucas. Frankfurt am Main: Meiner Verlag, 1992.

Hegel, G.W.F. Grundlinien der Philosophie des Rechts, Naturrecht und

Staatswissenschaft im Grundrisse - Grundlinien der Philosophie des Rechts.

Gesammelte Werke 14. Herausgegeben von Klaus Grotsch und Elisabeth Weisser-

Lohmann. Frankfurt am Main: Meiner Verlag, 2009.

—. Phänomenologie des Geistes. Gesammelte Werke 09. Herausgegeben von

Wolfgang Bonsiepen und Reinhard Heede. Frankfurt am Main: Meiner Verlag, 1980.

Kant, Immanuel. Bd 3 (I/3) Kritik der reinen Vernunft, (2. Aufl. 1787). Berlin; Boston:

De Gruyter, 1962.

Kervégan, Jean-François. "Introduction: l'institution de la liberté.” Principes de la philosophie du droit. Paris: Presses Universitaires de France, 2013.

Kojève, Alexandre, et Raymond Queneau. Introduction à la lecture de Hegel: leçons

sur la "Phénoménologie de l'esprit" professées de 1933 à 1939 à l'École des Hautes Études. Paris: Gallimard, 1979.

Lumsden, Simon. "The Rise of the Non-Metaphysical Hegel." Philosophy Compass 3, no. 1 (2008): 51-65.

Speight, A. "Arendt and Hegel on the Tragic Nature of Action." Philosophy \& Social

\begin{tabular}{|l|l|l|l|l|}
\hline Q Povista Dialectus & Ano 5 & n. 12 & Janeiro - Julho 2018 & p. 374-399 \\
\hline
\end{tabular}


Criticism 28, no. 5 (2002): 523-36.

Young-Bruehl, Elisabeth. Hannah Arendt: For Love of the World. New Haven: Yale

University Press, 1982.

\begin{tabular}{|c|c|c|c|c|}
\hline Romita Dialeatus & Ano 5 & n. 12 & Janeiro - Julho 2018 & p. $374-399$ \\
\hline
\end{tabular}

